\title{
The Relationship between Cultural Tightness-Looseness and Organizational Innovativeness: A Comparative Research into the Turkish and Italian Marble Industries
}

\author{
Emir Ozeren • Omur Neczan Timurcanday Ozmen • \\ Andrea Appolloni
}

Published online: 20 January 2013

(C) CEEUN 2013

\begin{abstract}
When examining the literature of cross-cultural field holistically, it can be seen that the dominant paradigm in the literature is based on values. However, in recent decades there have been growing criticisms against values in explaining cultural differences adequately and thus a new cultural dimension, the so called "tightness-looseness" has, once again, come to the forefront. The beginning point of this research is based on the assumption that cultural tightness-looseness, defined as strength, importance, pervasive and binding of norms within a certain community, which was previously examined on a societal level, might also have significant implications within organizations. In this regard, the ultimate objective of the research is to examine the validity and reliability of the construct in Turkish and Italian marble industries using a comparative approach, while considering the cultural dimension of tightness-looseness at an organizational level and aiming to explore its relationship with organizational innovativeness empirically. The survey method has therefore been adopted. The results and implications of the study are discussed in greater detail and recommendations for future studies made.
\end{abstract}

Keywords Tightness-looseness · Norm · Value - Organizational culture · Organizational innovativeness

JEL Classification $\mathrm{L} 10 \cdot \mathrm{M} 10$

\footnotetext{
E. Ozeren · O. N. T. Ozmen

Dokuz Eylul University, Izmir, Turkey

e-mail: emir.ozeren@deu.edu.tr

O. N. T. Ozmen

e-mail: omur.ozmen@deu.edu.tr

\author{
A. Appolloni ( $\square)$ \\ University of Rome Tor Vergata, Rome, Italy \\ e-mail: andrea.appolloni@uniroma2.it
}


The organization-level reflections of national (societal) culture dimensions have been widely discussed as part of cross-cultural studies. Yet, the way in which these dimensions were approached was mainly value-centric. However, the recently developing literature has discovered a new dimension of culture in explaining crosscultural differences. Being initially approached by Pelto (1968) on the basis of traditional societies, the cultural dimension of tightness-looseness today has become once again the focus of interest of theoretical discussions thanks to the studies carried out by Gelfand et al. (2006, 2011). They assert that the phenomenon of cultural tightness-looseness emerged as a reaction to the existing value-centric approaches. This situation resembles the long lasting problematic question in psychology: is it the personality or the environment that determines behaviour? While values are formed by the inner perceptions that the individual idealizes; the norms, on which the tightness-looseness dimension is based, express the actual state of the individual created by the external environment and restrictions. Thus, values focus on 'what should be' whereas norms focus on the actual ("de facto") status. For gaining the exact understanding of the cross-cultural similarities and differences, the norms, as the other side of the coin, should be taken into consideration.

In sum, tightness-looseness is a currently developing cultural phenomenon. This has very recently attracted the attention of the researchers (Toh and Leonardelli 2012; Gelfand et al. 2011) studying cross-cultural differences and the cultural dimension of tightness-looseness has started to be questioned on theoretical grounds and its distinction from the existing cultural dimensions has been realized. In the light of the current literature there seems to be a paucity of organizational level research on cultural tightness-looseness and this study aims to fulfil this void. The tightness-looseness dimension is a relatively new concept and it has not been sufficiently examined in organizational culture literature, except for a few studies (Wasti and Fiş 2010). Gelfand et al. (2006), p 1226 define tightness-looseness as the "strength of social norms and the degree of sanctioning" available in a given community. In other words, cultural tightness-looseness can be explained as how clear and pervasive norms are within a given community and how much tolerance exists for deviance from such norms. Gelfand et al. (2006) indicate that the cultural dimension of tightness-looseness has important effects at individual, societal and organization levels and emphasize the necessity of examining the concept at these levels in future studies. From this point, the aim of the current study is to examine the tightness-looseness construct at an organizational level, as it was previously examined at a societal level (Gelfand et al. 2011; Chan et al. 1996; Pelto 1968) and try to empirically determine its relationship with organizational innovativeness. The research questions developed based on this aim are as follows:

- Is the cultural dimension of tightness-looseness a relevant and valid construct for Turkish and Italian marble enterprises?

- To what extent can Turkish and Italian marble enterprises be considered as "tight" or "loose"? 
- To what extent are Turkish and Italian marble enterprises are able to reflect the cultural tightness-looseness of their own society in which they are operating?

- Is there a significant relationship between tightness-looseness and organizational innovativeness?

- Can organizational innovativeness be affected by tight or loose characteristics of the organization?

- Does the effect of cultural tightness-looseness on organizational innovativeness vary from one country to the other?

\section{Methodology}

\section{Research Model}

Within the framework of the study, the cultural tightness-looseness dimension is regarded as an independent variable, the country variable as a moderator variable and organizational innovativeness as a dependent variable Fig. 1.

\section{Sample and Data Collection}

The study was conducted in Turkish and Italian business contexts. The target sector was selected as the marble and natural stone industry in which both countries are strong. As a matter of fact the two biggest marble fairs of the world are held annually in Verona-Italy and Izmir-Turkey. The study was carried out in the quarryowning businesses that are in the producer position. In determining the sample, rather than including Turkish and Italian units of one multinational company, various SMEs from both countries that can represent the sector were incorporated. Instead of selecting one participant to represent each enterprise, several employees of each company were included as far as possible to reduce single informant bias Table 1.

The main data source for Turkish sample was from the enterprises operating in the Aegean region of Turkey. Marble production of the cities in this region constitutes $65 \%$ of the total production in Turkey. Approximately 75-80\% of the manufactured natural stone is processed and turned into products with high added

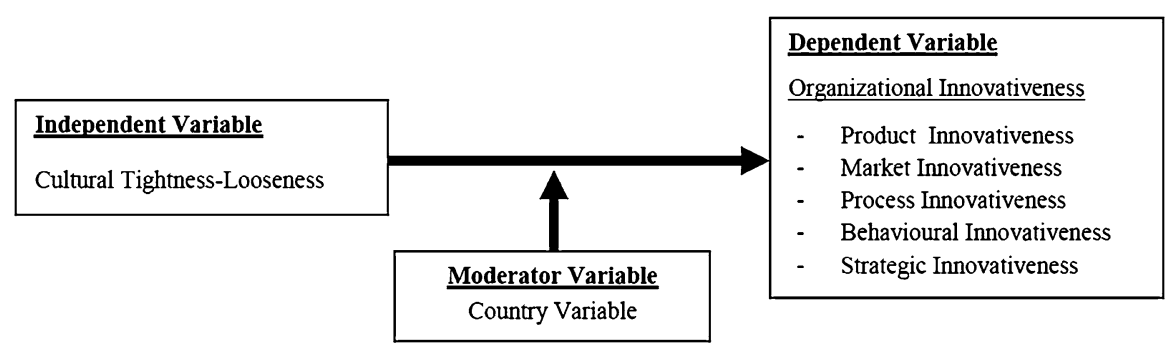

Fig. 1 Research model 
value in this region. At the end of the data collection process, 126 usable questionnaires were obtained from Turkey. As for Italian sample, the geographical regions where marble producers are densely located are as follows: Carrara, Verona and Sicily. The Carrara region, to which the researcher had the greatest means of access, was selected for the sample. Carrara, along with Verona, comes forth as the industrial clustering area of the marble producing sector in Italy. By the end of the process, 125 usable questionnaires were collected.

\section{Measures}

As the major data collection tool, a survey with three subsections was adopted for the study. In the first section, the cultural tightness-looseness dimension was measured by six items which were originally developed for societal level by Gelfand et al. (2011). Those were adapted from societal to organizational level for the first time in this study. In the second section 20 items were prepared in order to measure organizational innovativeness based on the scale designed by Wang and Ahmed (2004) (items 1-4 are product innovativeness, 5-8 are market innovativeness, 9-12 process innovativeness, 13-16 behavioural innovativeness and 17-20 strategic innovativeness). In the last section seven demographic questions were included in order to determine participants' gender, age, education level, current unit and position, working experience. The tightness-looseness and organizational innovativeness items were ranked using a 6-point Likert type scale (1: strongly disagree..., 6: strongly agree) with a higher score indicating a greater tightness or innovativeness.

\section{Findings}

\section{Validity and Reliability Analysis}

In order to determine the content validity of the scales in the phase of developing the questionnaire form, first the opinions of field experts were sought and the literature on tightness-looseness and organizational innovativeness was reviewed in depth. Since the study was carried out in different cultures, the opinions of three scholars one from Turkey, one from Italy and one from the USA were taken as a base and these experts were kindly requested to evaluate the clarity and the content validity of the items. Validity and reliability analyses were carried out separately for each sample. In determining the factor structures of tightness-looseness and organizational innovativeness scales, an exploratory factor analysis method (principal components analysis and varimax rotation) was employed. The items with a factor load of 0.4 and higher were taken into consideration, and when determining the number of factors in the data reduction stage the factors with one or a higher eigenvalue were selected. Also, when determining the final factor structure, the scree plot of factors was also taken into consideration. Items were loaded on the factors explained in the theory and the factor structures in both samples were found to be similar to a great extent. Considering the KMO value and Bartlett tests of 
tightness-looseness and organizational innovativeness scales, it can be seen that the data are appropriate to carry out factor analysis in both samples. Having conducted the factor analysis for the tightness-looseness scale for each sample, the total number of items were reduced from 6 to 4, and these four items were grouped under a single dimension and all their factor loads were above 0.40. Due to the fact that item number four considerably reduced reliability in the tightness-looseness scale, this item was removed from the analysis in both samples. Similarly, Gelfand et al. (2011) p 3 point to the problematic structure caused by the low factor load and reliability of item number four in the tightness-looseness scale. Because of the fact that the factor load of item number six in the sample from Turkey was below 0.40, and item number five in the sample from Italy was loaded to another factor, these two items were omitted from the scope of the analysis. Consistent with the findings of Gelfand et al. (2011), the tightness-looseness scale was found to be unidimensional in this study Table 2.

Table 1 Demographic findings

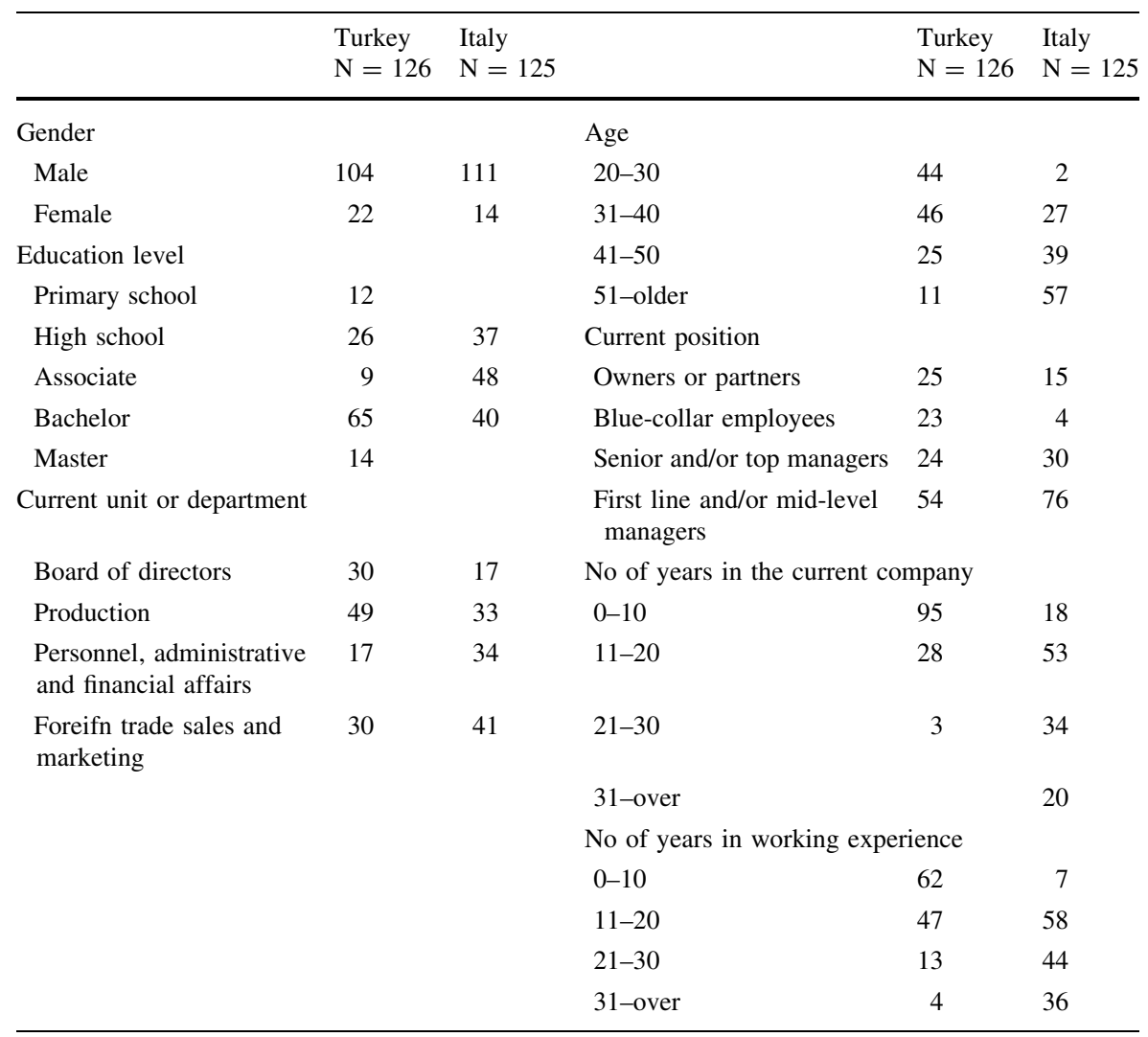


Table 2 Factor loadings of cultural tightness-looseness scale

\begin{tabular}{ll}
\hline Turkish sample $^{\mathrm{a}, \mathrm{b}}$ & \\
Item number & Factor loadings \\
1 & 0.540 \\
2 & 0.848 \\
3 & 0.829 \\
5 & 0.774 \\
\hline Italian sample ${ }^{\mathrm{c}, \mathrm{d}}$ & \\
Item number & Factor loadings \\
1 & 0.855 \\
2 & 0.836 \\
3 & 0.765 \\
6 & 0.753 \\
\hline${ }^{\mathrm{a}}$ Total variance explained $=0.57$ & \\
${ }^{\mathrm{b}} \mathrm{KMO}=0.71$ Bartlett test $=0.000^{*}\left(\mathrm{X}^{2}: 134.208 \mathrm{df}: 6 \mathrm{p}<0.05\right)$ & \\
${ }^{\mathrm{c}}$ Total variance explained $=0.65$ & \\
${ }^{\mathrm{d}} \mathrm{KMO}=0.71$ Bartlett test $=0.000^{*}\left(\mathrm{X}^{2}: 189.539 \mathrm{df}: 6 \mathrm{p}<0.05\right)$ & \\
\end{tabular}

As a result of the factor analysis conducted for the organizational innovativeness scale for both samples, the total number of items were reduced from 20 to 16, and the remaining 16 items were distributed between 3 factors and their factor loads were above 0.40 as shown in Table 3 . The item numbers 4, 5, 17 and 20 of the organizational innovativeness scale were excluded from the scope of the analysis. The common characteristic of these four items is that they are all reverse coded. It was determined that these reverse coded items tend to gather under the same factor. Also in other studies that utilized the same scale (Wang and Ahmed 2004) researchers excluded these four items from the analysis due to their problematic structure (e.g. Semerciöz et al. 2011; Ellonen et al. 2008). The factor analysis shows that the items concerning product and market innovativeness are gathered under the same factor. This finding is consistent with the literature on innovativeness since product and market innovativeness are generally regarded as intertwined concepts that are in a very close interaction and relation with one another. As the criterion with which scale reliability is measured $(\alpha>0.70)$ cronbach's alpha value was taken as the basis (Nunnally 1978). In this respect the main variables of the study are likely to fulfil this criterion as shown in Table 5.

The difference between the mean scores of both samples from the cultural tightness-looseness and innovativeness scales was tested via $t$ test and the results are presented in Table 4. From the values presented in the significance column of the table, it can be seen that the difference between the two groups is statistically significant at $\mathrm{p}<0.01$ level for all dimensions. The mean scores of both samples from the tightness-looseness and organizational innovativeness scales are shown in Table 5. The values indicate that in all dimensions the Italian sample has higher 
Table 3 Factor loadings of organizational innovativeness scale

\begin{tabular}{|c|c|c|c|c|}
\hline \multirow{2}{*}{$\begin{array}{l}\text { Table } 3 \text { Factor loadings of } \\
\text { organizational innovativeness } \\
\text { scale }\end{array}$} & \multicolumn{4}{|c|}{ Factor loadings of org. innovativeness scale } \\
\hline & Item & Product and market & Process & Behavioural \\
\hline & \multicolumn{4}{|c|}{ Italy $^{\mathrm{a}, \mathrm{b}}$} \\
\hline & 1 & 0.49 & & \\
\hline & 2 & 0.60 & & \\
\hline & 3 & 0.71 & & \\
\hline & 6 & 0.80 & & \\
\hline & 7 & 0.82 & & \\
\hline & 8 & 0.72 & & \\
\hline & 9 & & 0.63 & \\
\hline & 10 & & 0.84 & \\
\hline & 11 & & 0.69 & \\
\hline & 12 & & 0.61 & \\
\hline & 13 & & & 0.66 \\
\hline & 14 & & & 0.71 \\
\hline & 15 & & & 0.69 \\
\hline & 16 & & & 0.71 \\
\hline & 18 & & & 0.85 \\
\hline & 19 & & & 0.84 \\
\hline & \multicolumn{4}{|c|}{ Turkey ${ }^{\mathrm{a}, \mathrm{c}}$} \\
\hline & 1 & 0.45 & & \\
\hline & 2 & 0.59 & & \\
\hline & 3 & 0.74 & & \\
\hline & 6 & 0.75 & & \\
\hline & 7 & 0.74 & & \\
\hline & 8 & 0.68 & & \\
\hline & 9 & & 0.533 & \\
\hline & 10 & & 0.563 & \\
\hline & 11 & & 0.501 & \\
\hline \multirow{2}{*}{$\begin{array}{l}\text { Total variance } \\
\text { explained }=0.67\end{array}$} & 15 & & 0.816 & \\
\hline & 18 & & 0.718 & \\
\hline \multirow{3}{*}{$\begin{array}{l}\text { b } \mathrm{KMO}=0.83 \text { Bartlett } \\
\text { test }=0.000^{*}\left(\mathrm{X}^{2}: 1210.437\right. \\
\text { df; } 120 \mathrm{p}<0.05)\end{array}$} & 19 & & 0.828 & \\
\hline & 12 & & & 0.654 \\
\hline & 13 & & & 0.840 \\
\hline \multirow{2}{*}{$\begin{array}{l}\text { c } \mathrm{KMO}=0.88 \text { Bartlett } \\
\text { test }=0.000^{*}\left(\mathrm{X}^{2}: 1303.825\right. \\
\mathrm{df} ; 120 \mathrm{p}<0.05)\end{array}$} & 14 & & & 0.770 \\
\hline & 16 & & & 0.680 \\
\hline
\end{tabular}

points than the Turkish sample. Considering this finding along with the findings of the $t$ test provides the conclusion that, Italian marble enterprises have a tighter culture and exhibit more innovative characteristics compared to their Turkish counterparts. 
Table $4 t$ test results for Turkish and Italian samples

\begin{tabular}{|c|c|c|c|c|c|}
\hline & \multicolumn{2}{|c|}{ Level test } & \multicolumn{3}{|l|}{$t$ test } \\
\hline & $\mathrm{F}$ & Sig. & $\mathrm{t}$ & df & Sig. \\
\hline \multicolumn{6}{|l|}{ Tightness-looseness } \\
\hline Equal of variances assumed & 23.821 & 0.000 & -4.211 & 249 & 0.000 \\
\hline Not equal of variances assumed & & & -4.219 & 207.998 & 0.000 \\
\hline \multicolumn{6}{|l|}{ Behavioural innov. } \\
\hline Equal of variances assumed & 21.405 & 0.000 & -2.624 & 249 & 0.009 \\
\hline Not equal of variances assumed & & & -2.627 & 223.830 & 0.009 \\
\hline \multicolumn{6}{|l|}{ Product-market innov } \\
\hline Equal of variances assumed & 15.786 & 0.000 & -3.444 & 249 & 0.001 \\
\hline Not equal of variances assumed & & & -3.450 & 212.479 & 0.001 \\
\hline \multicolumn{6}{|l|}{ Process innov. } \\
\hline Equal of variances assumed & 66.608 & 0.000 & -4.510 & 249 & 0.000 \\
\hline Not equal of variances assumed & & & -4.520 & 188.181 & 0.000 \\
\hline
\end{tabular}

Table 5 Tightness-looseness and org. innovativeness profiles for Turkish and Italian samples

\begin{tabular}{llllllll}
\hline & Country & $\mathrm{N}$ & Mean & Std dev & Std error & Cronbach alpha scores \\
\hline Tightness-looseness & Turkey & 126 & 4.48 & 0.94755 & 0.08441 & 0.73 & \\
& Italy & 125 & 4.90 & 0.58272 & 0.05212 & & 0.81 \\
Behavioural innov. & Turkey & 126 & 4.20 & 0.95850 & 0.08539 & 0.78 & \\
& Italy & 125 & 4.47 & 0.97050 & 0.05997 & & 0.89 \\
Product-market innov & Turkey & 126 & 4.02 & 0.96655 & 0.08611 & 0.81 & \\
& Italy & 125 & 4.38 & 0.61632 & 0.05513 & & 0.88 \\
Process innov. & Turkey & 126 & 4.25 & 1.04683 & 0.09326 & 0.88 & \\
& Italy & 125 & 4.73 & 0.54364 & 0.04862 & & 0.77 \\
\hline
\end{tabular}

The Relationship between Cultural Tightness-Looseness and Organizational Innovativeness

The relationship between cultural tightness-looseness and organizational innovativeness was examined via correlation analysis, as depicted in Table 6. In the Turkish sample, tightness-looseness was positively related to process innovativeness whereas it is inversely related to behavioural innovativeness. The relationship between tightness-looseness and product-market innovativeness was found to be insignificant. In the Italian sample, the tightness-looseness was positively related to all organizational innovativeness sub-dimensions.

The Effects of Cultural Tightness-Looseness on Sub-dimensions of Organizational Innovativeness

In this section, a series of simple regression analysis were carried out for each sample in order to reveal the effects of cultural tightness-looseness on sub- 
Table 6 The correlation between tightness-looseness (T-L) and organizational innovativeness

\begin{tabular}{|c|c|c|c|c|c|c|c|c|}
\hline & \multicolumn{4}{|c|}{ Turkish sample } & \multicolumn{4}{|c|}{ Italian sample } \\
\hline & $\mathrm{T}-\mathrm{L}$ & $\mathrm{B} / \mathrm{l}$ & $\begin{array}{l}\text { Product- } \\
\text { market inn. }\end{array}$ & $\begin{array}{l}\text { Process } \\
\text { 1nn }\end{array}$ & $\mathrm{T}-\mathrm{L}$ & $\mathrm{B} / \mathrm{I}$ & $\begin{array}{l}\text { Product- } \\
\text { market inn }\end{array}$ & $\begin{array}{l}\text { Process } \\
\text { 1nn }\end{array}$ \\
\hline $\mathrm{T}-\mathrm{L}$ & 1 & $-0.31 * *$ & 0.17 & $0.40^{* * *}$ & 1 & $0.49 * *$ & $0.59 * *$ & $0.42 * *$ \\
\hline $\begin{array}{r}\text { Behavioural } \\
\text { innov }(\mathrm{B} / \mathrm{I})\end{array}$ & $-0.31^{* *}$ & 1 & $0.34 * *$ & $0.31 * *$ & $0.49 * *$ & 1 & $0.60 * *$ & $0.60 * *$ \\
\hline $\begin{array}{c}\text { Product- } \\
\text { market } \\
\text { innov }\end{array}$ & 0.17 & $0.34 * *$ & 1 & $0.66^{* * *}$ & $0.59 * *$ & $0.60 * *$ & 1 & $0.58 * *$ \\
\hline Process innov. & $0.40 * *$ & $0.31 * *$ & $0.66^{* *}$ & 1 & $0.42 * *$ & $0.60 * *$ & $0.58 * *$ & 1 \\
\hline
\end{tabular}

$\left({ }^{* *} \mathrm{p}<0.01\right)$

dimensions of organizational innovativeness (product-market, process, behavioural) respectively Tables $7,8,9,10,11,12$.

\section{The Moderator Role of the Country Variable on the Relationship between Cultural Tightness-Looseness and Organizational Innovativeness}

In this section the effect of cultural tightness-looseness on sub-dimensions of organizational innovativeness (product and market, process, behavioural) was measured by two-stage regression analyses with which the differentiation of Turkey and Italy as country variables was taken into account. In examining whether the moderator effect of the country variable was significant on the relationship between the tightness-looseness dimension and organizational innovativeness, multiple regression analysis in which the interaction term was included, was employed. A stepwise method was followed to include the independent variables in the model. All the analyses were conducted by following strictly the procedures suggested by Aiken and West (1991) pp 116-137 for explaining the interaction between

Table 7 The effect of tightness-looseness (TL) on product-market innovativeness (Turkish sample)

\begin{tabular}{lllllll}
\hline Model & $\mathrm{R}$ & $\mathrm{R}^{2}$ & Adj. $\mathrm{R}^{2}$ & Std error & $\mathrm{F}$ & Sig. \\
\hline $\mathrm{Y}=\mathrm{bO}+\mathrm{B}(\mathrm{TL})$ & 0.165 & 0.027 & 0.019 & 0.95712 & 3.475 & 0.065 \\
\hline$(\mathrm{p}=0.065<0.05)$ & & & &
\end{tabular}

Table 8 The effect of tightness-looseness (TL) on process innovativeness (Turkish sample)

\begin{tabular}{lllllll}
\hline Model & $\mathrm{B}$ & $\mathrm{R}^{2}$ & Adj. $\mathrm{R}^{2}$ & Std error & $\mathrm{F}$ & Sig. \\
\hline $\mathrm{Y}=\mathrm{bO}+\mathrm{B}(\mathrm{TL})$ & 0.444 & 0.16 & 0.15 & 0.962 & 23.948 & $0.000^{*}$ \\
\hline$(* \mathrm{p}=0.000<0.05)$ & & & & & &
\end{tabular}


Table 9 The effect of tightness-looseness (TL) on behavioural innovativeness (Turkish sample)

\begin{tabular}{lllllll}
\hline Model & $\mathrm{B}$ & $\mathrm{R}^{2}$ & Adj. $\mathrm{R}^{2}$ & Std error & $\mathrm{F}$ & Sig. \\
\hline $\mathrm{Y}=\mathrm{bO}+\mathrm{B}(\mathrm{TL})$ & -0.310 & 0.094 & 0.087 & 0.91597 & 12.877 & $0.000^{*}$ \\
\hline$\left.{ }^{*} \mathrm{p}=0.000<0.05\right)$ & & & & & &
\end{tabular}

Table 10 The effect of tightness-looseness (TL) on product-market innovativeness (Italian sample)

\begin{tabular}{lllllll}
\hline Model & $\mathrm{B}$ & $\mathrm{R}^{2}$ & Adj. $\mathrm{R}^{2}$ & Std error & $\mathrm{F}$ & Sig. \\
\hline $\mathrm{Y}=\mathrm{bO}+\mathrm{B}(\mathrm{TL})$ & 0.619 & 0.34 & 0.33 & 0.50180 & 64.054 & $0.000^{*}$ \\
\hline$\left.{ }^{*} \mathrm{p}=0.000<0.05\right)$ & & & & & &
\end{tabular}

Table 11 The effect of tightness-looseness (TL) on process innovativeness (Italian sample)

\begin{tabular}{lllllll}
\hline Model & $\mathrm{B}$ & $\mathrm{R}^{2}$ & Adj. $\mathrm{R}^{2}$ & Std error & $\mathrm{F}$ & Sig. \\
\hline $\mathrm{Y}=\mathrm{bO}+\mathrm{B}(\mathrm{TL})$ & 0.390 & 0.18 & 0.17 & 0.49590 & 26.023 & $0.000^{*}$ \\
\hline$(* \mathrm{p}=0.000<0.05)$ & & & & & &
\end{tabular}

Table 12 The effect of tightness-looseness (TL) on behavioral innovativeness (Italian sample)

\begin{tabular}{lllllll}
\hline Model & $\mathrm{B}$ & $\mathrm{R}^{2}$ & Adj. $\mathrm{R}^{2}$ & Std error & $\mathrm{F}$ & Sig. \\
\hline $\mathrm{Y}=\mathrm{bO}+\mathrm{B}(\mathrm{TL})$ & 0.567 & 0.24 & 0.23 & 0.58579 & 39.455 & $0.000^{*}$ \\
\hline$(* \mathrm{p}=0.000<0.05)$ & & & & & &
\end{tabular}

categorical and continuous variables. For a graphical illustration of regression curves, the same source was again utilized and the "post hoc probing of significant interactions" method was employed.

The Evaluation of the Effect of Cultural Tightness-Looseness (TL) Dimension on Product and Market Innovativeness with Respect to Turkey and Italy

In order to determine the effect of cultural tightness-looseness (TL) on product and market innovativeness with respect to Turkey and Italy (with the moderator effect of a country variable), the country variable and TL interaction term were also included in the regression model besides the main effects of dependent and independent variables. Accordingly, the regression equation $\mathrm{Y}=\mathrm{b} 0+(\mathrm{b} 1)(\mathrm{TL})+(\mathrm{b} 2)(\mathrm{COUN}-$ TRY $)+(\mathrm{b} 3)(\mathrm{TL} \times \mathrm{COUNTRY})$ is statistically significant with a $5 \%$ margin of error. The point that requires particular attention in moderator analysis is the statistical significance of the interaction term in the regression model. It can be seen that the TL $\times$ COUNTRY interaction term is statistically significant with $5 \%$ error margin. Thus, the relationship between cultural tightness-looseness and productmarket innovativeness is likely to differ at a country level. Based on the coefficients 
from the Table 13, the regression equation was as follows: $Y=4.064+$ $0.168(T L)+0,188($ COUNTRY $)+0.451(T L \times C O U N T R Y)$.

In order to examine the moderator effect of the country variable, the general regression equation had to be rearranged for Turkey and Italy. Since the country variable is a categorical variable, Turkey was coded as 0 and Italy as 1 . When this coding was inserted into the general regression equation, the equations according Turkey and Italy were formed as follows:

TURKEY: $Y=4.064+0.168(T L)+0.188(0)+0.451(T L \times 0)=4.064+$ $0.168(T L)$

ITALY: $Y=4.064+0.168(T L)+0.188(1)+0.451(T L \times 1)=4.252+$ $0.619(T L)$

The regression equations of the respective countries were drawn in the graphic (see Fig. 2). Accordingly, when the tightness level increases, product and market innovativeness also increases in both samples. Another important point that should

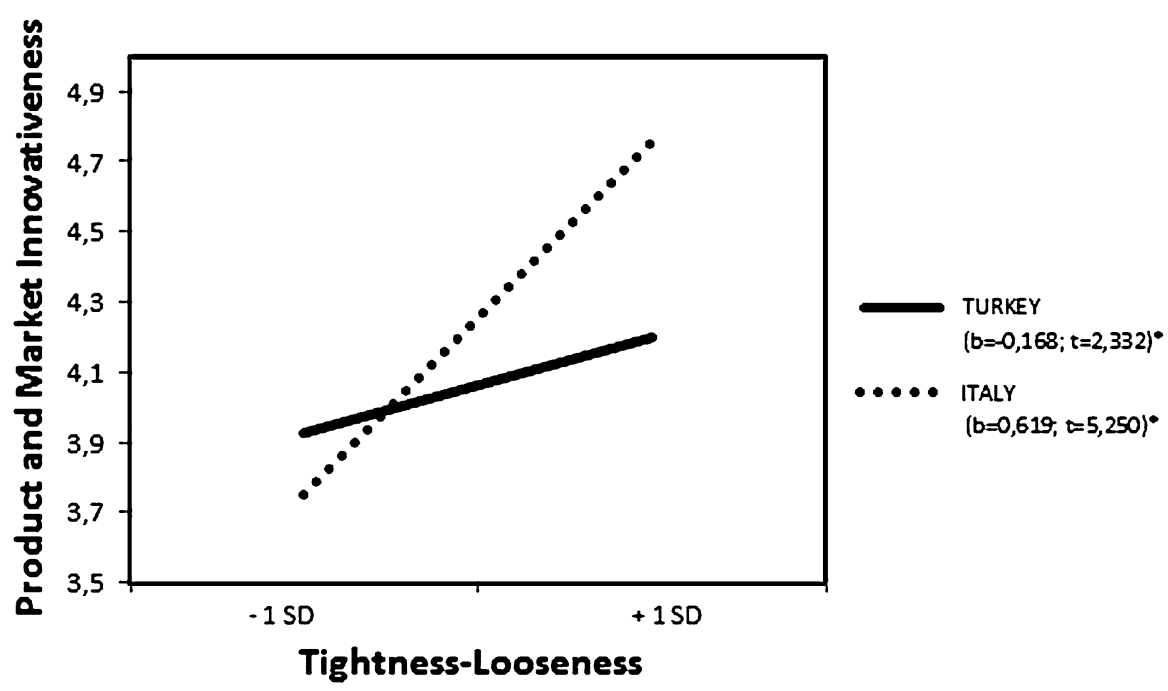

Fig. 2 Graphical representation of the regression equation

Table 13 The moderation analysis based on the effect of tightness-looseness (TL) on product-market innovativeness with respect to Turkey and Italy

\begin{tabular}{lcccc}
\hline \multicolumn{1}{l}{ Model } & & Adj. R & Std error & Sig. \\
\hline $\mathrm{Y}=\mathrm{b} 0+(\mathrm{b} 1)(\mathrm{TL})+(\mathrm{b} 2)(\mathrm{COUNTRY})+(\mathrm{b} 3)(\mathrm{TL} \times$ COUNTRY $)$ & 0.148 & 0.76504 & $0.000^{*}$ \\
\hline Model & $\mathrm{B}$ & Std error & $\mathrm{t}$ & Sig. \\
\hline Constant & 4.064 & 0.070 & 58.221 & $0.000^{*}$ \\
T-L & 0.168 & 0.072 & 2.332 & $0.021^{*}$ \\
COUNTRY & 0.188 & 0.101 & 1.861 & 0.064 \\
TL $\times$ COUNTRY & 0.451 & 0.138 & 3.258 & $0.001^{*}$ \\
\hline
\end{tabular}

$(* \mathrm{p}<0.05)$ 
Table 14 The moderation analysis based on the effect of tightness-looseness (T-L) on process innovativeness with respect to Turkey and Italy

\begin{tabular}{lccccc}
\hline \multicolumn{1}{l}{ Model } & & Adj. ${ }^{2}$ & Std error & Sig. \\
\hline Y $=\mathrm{b} 0+(\mathrm{b} 1)(\mathrm{TL})+(\mathrm{b} 2)($ COUNTRY $)+(\mathrm{b} 3)(\mathrm{TL} \times$ COUNTRY $)$ & 0.22 & 0.77 & $0.000^{*}$ \\
\hline Model & $\mathrm{B}$ & Std error & $\mathrm{t}$ & & Sig. \\
\hline Constant & 4.349 & 0.070 & 62.207 & $0.000^{*}$ \\
T-L & 0.444 & 0.072 & 6.145 & $0.000^{*}$ \\
COUNTRY & 0.301 & 0.101 & 2.978 & $0.003^{*}$ \\
TL $\times$ COUNTRY & -0.055 & 0.138 & -0.394 & 0.694 \\
\hline
\end{tabular}

$(* \mathrm{p}<0.05)$

not be overlooked is that the graphic of the regression line for Turkey is more horizontal and the regression line for Italy is more vertical due to their slope. While the increase in the tightness level for the Italian sample causes a positive and a higher increase in product and market innovativeness, the increase in the tightness level also produces positive but a lower increase in the Turkish sample when compared to the Italian one.

The Evaluation of the Effect of Cultural Tightness-Looseness (TL) Dimension on Process Innovativeness with Respect to Turkey and Italy

The coefficients and significance levels of the variables in the regression equation are presented in Table 14 and were statistically significant with a $5 \%$ margin of error. However, the TL $\times$ COUNTRY interaction was statistically insignificant. Accordingly, it can be stated that the effect of tightness-looseness on process innovativeness is unlikely to exhibit a significant difference at a country level.

The Evaluation of the Effect of Cultural Tightness-Looseness (TL) Dimension on Behavioural Innovativeness with Respect to Turkey and Italy

The coefficients, significance levels of the variables in the regression equation and the TL $\times$ COUNTRY interaction was found to be statistically significant. It can be

Table 15 The moderation analysis based on the effect of tightness-looseness (TL) on behavioural innovativeness with respect to Turkey and Italy

\begin{tabular}{lccccc}
\hline Model & & Adj. ${ }^{2}$ & Std error & Sig. \\
\hline $\mathrm{Y}=\mathrm{b} 0+(\mathrm{b} 1)(\mathrm{TL})+(\mathrm{b} 2)(\mathrm{COUNTRY})+(\mathrm{b} 3)(\mathrm{TL} \times$ COUNTRY $)$ & 0.16 & 0.79 & $0.000^{*}$ \\
\hline Model & $\mathrm{B}$ & Std error & $\mathrm{t}$ & & Sig. \\
\hline Constant & 4.038 & 0.070 & 58.940 & $0.000^{*}$ \\
T-L & -0.310 & 0.073 & -4.272 & $0.000^{*}$ \\
COUNTRY & 0.220 & 0.101 & 2.166 & $0.031^{*}$ \\
TL $\times$ COUNTRY & 0.877 & 0.139 & 6.309 & $0.000^{*}$ \\
\hline
\end{tabular}

$(* \mathrm{p}<0.05)$ 


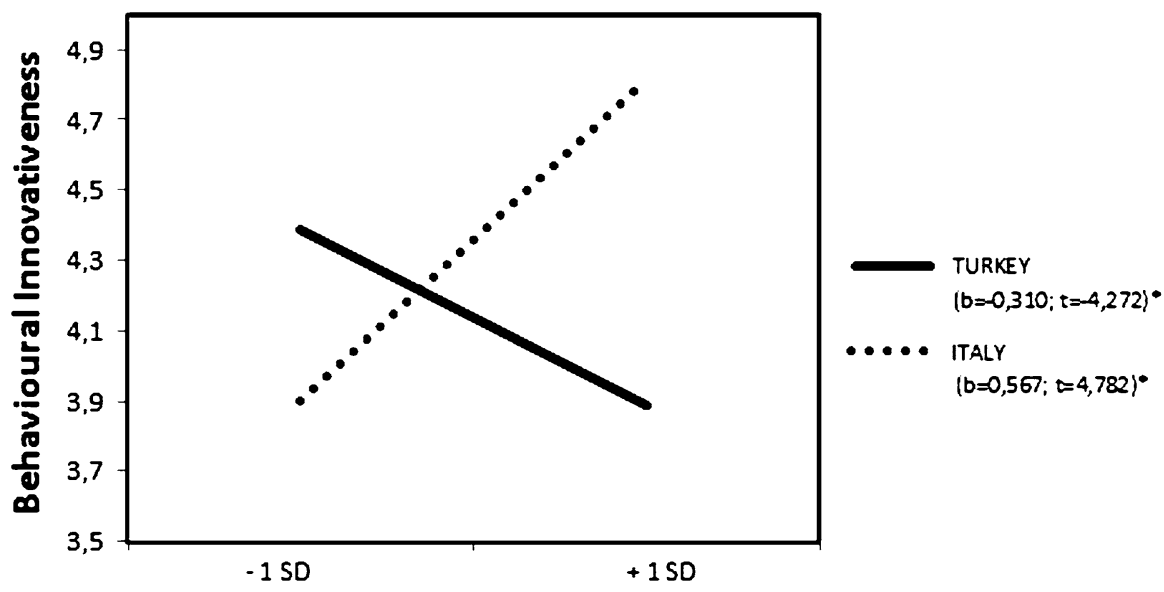

Tightness-Looseness

Fig. 3 Graphical representation of the regression equation

said that the effect of cultural tightness-looseness on behavioural innovativeness is likely to differ at a country level.

The regression equation based on the coefficients from Table 15 is as follows: $Y=4.138-0.310(T L)+0.220($ COUNTRY $)+0.877(T L \times C O U N T R Y)$. In order to examine the moderator effect of the country variable, the general regression equation had to be rearranged for both Turkey and Italy. Since the country variable was a categorical variable, Turkey was coded as 0 and Italy as 1 . When this coding was inserted into the general regression equation, the equations according Turkey and Italy were as follows:

TURKEY: $\quad Y=4.138-0.310(T L)+0.220(0)+0.877(T L \times 0)=4.138-$ $0.310(T L)$

ITALY: $\quad Y=4.138-0.310(T L)+0.220(1)+0.877(T L \times 1)=4.358+$ $0.567(T L)$

The regression equations of the respective countries were drawn in the Fig. 3. Accordingly, when the level of tightness increases, behavioural innovativeness decreases for the Turkish sample whereas it increases for the Italian sample. It is a remarkable finding that the effect of the cultural tightness-looseness dimension on behavioural innovativeness seems to be contrary for the two countries.

\section{Discussion}

Considering the results of this study, it is possible to infer that organizational culture can share the general features of a national culture. Namely, the Turkish and Italian marble enterprises were found to have tight cultural characteristics based on the above-mean scores for the tightness-looseness scale. Similarly, Gelfand et al. (2010) p 53 classified Turkey and Italy under the same category as societies 
manifesting rather tight attributes. In this respect, it can be asserted that organizations are likely to reflect the cultural characteristics of the society in which they are engaged. Organizations within a societal/national culture where tightness is dominant are expected to exhibit tight characteristics.

The traditional structure prevalent in the Turkish marble industry, paternalistic values (Aycan 2001), and the dominant role of the family members on companies' management processes seem to be factors that contribute to high levels of tightness for the Turkish sample. Aycan and Kanungo (2000) report that in paternalistic cultures the duty of the superiors is to protect, direct and guide the subordinates, while the subordinates' duty is to unconditionally obey the superior. In societies where paternalistic tendencies are high it is expected that compliance with the established organizational rules and norms is important. Therefore, having high paternalism is likely to point to a tight culture. Consistent with this point, participants in the Turkish sample who are in the "board of directors" and "owners or partners" of their companies scored relatively higher points than those working in other departments and positions in terms of the tightness-looseness dimension. These findings are likely to indicate the high perception of tightness in Turkish marble enterprises, particularly from the viewpoint of top management. Another remarkable finding of this study is that Italian marble companies were found to be culturally tighter than their Turkish counterparts. The majority of Italian participants were between the ages of 40 and 50 and had worked for the same company for at least 20 or 30 years. It was even found that, in the Italian sample, the participants who worked for the same company for nearly all their working life were in the majority. Keeping all of these findings in mind, it is possible to assert that Italian respondents might have had a stronger tendency to comply with the norms set by their organizations so that their cultural tightness score was found to be relatively higher.

It was also determined that, in terms of three sub-dimensions of organizational innovativeness (product-market, process and behavioural), the innovativeness perception of Italian companies was higher than that of their Turkish counterparts. This can be explained by the fact that Italian marble companies have a deep rooted history, tradition, knowledge, expertise and experience in the field, they utilize the benefits of having penetrated the market earlier, and they have relative superiority in terms of technology, $R \& D$, branding and design. As a matter of fact, besides the rich marble and granite reserves it has, Italy also holds its position as the centre of production and processing technology. Turkey also has an important place in the world's natural stone market with its geological structure, variety of marbles and reserves magnitude. In spite of having a strong potential in terms of quantity and quality particularly in carbonated marble, Turkey is not in the position it deserves in the world market. The Turkish marble and natural stone industry has achieved partial improvements in terms of market awareness, customer and product base, but it can be seen that few improvements have been made in terms of R\&D support and investments, co-operations, networks and clusters in the sector, perception of innovativeness, vision and management mentality of company owners and managers (Aegean Exporters' Associations Sectoral Report 2011 p 6). The finding that the Turkish marble businesses had a lower level of innovativeness than their Italian counterparts indicates that the Turkish sector needs improvements in areas 
such as innovative investments and the use of $R \& D$ and high technology. The lack of an established $R \& D$ culture and the inadequacy of the resources allocated for $\mathrm{R} \& \mathrm{D}$ in the Turkish marble and natural stone industry are in evidence.

The presence of a significant relationship between cultural tightness-looseness and the sub-dimensions of organizational innovativeness was noted in the study. In the Turkish sample can be seen a negative relationship between tightness-looseness and behavioural innovativeness, and a positive relationship between tightnesslooseness and process innovativeness. However, the relationship between tightnesslooseness and product/market innovativeness was not statistically meaningful. Considering these findings, it can be asserted that as the cultural tightness level increases process innovativeness is likely to increase whereas behavioural innovativeness is likely to decrease in the Turkish sample. In the Italian sample was found a positive relationship between cultural tightness-looseness and all sub-dimensions of organizational innovativeness including product-market, process and behavioural. Based on this finding, it can be stated that as the cultural tightness level increases; behavioural, product/market and process innovativeness are likely to increase for the marble enterprises included in the Italian sample. The findings of the current study are consistent with (Wasti and Fis 2010)'s findings. Similarly, (Wasti and Fis 2010 p 24) determine that the tightness-looseness dimension was positively related to certain organization-level variables such as entrepreneurship and innovativeness.

Having investigated the causality between tightness-looseness and sub-dimensions of organizational innovativeness via simple regression analyses, a positive effect of tightness-looseness on process innovativeness, an inverse effect of tightness-looseness on behavioural innovativeness and an insignificant effect of tightness-looseness on product-market innovativeness for the Turkish sample were all revealed. On the other hand, the positive effect of tightness-looseness on all dimensions of organizational innovativeness (product-market, process and behavioural) was determined for the Italian sample. These results imply that cultural tightness-looseness in both samples can be influential on the sub-dimensions of organizational innovativeness. In a similar vein, Fiş and Wasti (2010) p 616 examined the effects of cultural dimensions (individualism-collectivism, power distance, tightness-looseness) on entrepreneurial orientation and innovativeness through hierarchical multiple regression analysis and they also pointed to the statistically meaningful effect of the tightness-looseness dimension on organizational variables such as innovativeness and entrepreneurial orientation.

One of the most critical findings of the research was the moderating role of the country variable on the interaction between cultural tightness-looseness and organizational innovativeness sub-dimensions. It was revealed that the effect of tightness-looseness on organizational innovativeness sub-dimensions shows a differentiation between Turkey and Italy. This might be interpreted as a notable finding that points to a cross-cultural difference between the two samples. Accordingly, when the tightness level increases (in other words looseness decreases), product and market innovativeness is likely to increase in both samples but with a higher increase in the Italian sample when compared to the Turkish sample. It was found that the effect of the cultural tightness-looseness dimension on behavioural innovativeness differs at a country level. It can be seen that as the level of tightness 
increases (namely, looseness decreases), behavioural innovativeness decreases for the Turkish sample, whereas an increase in the level of tightness triggers an increase in behavioural innovativeness for the Italian sample. It is a remarkable finding that the effect of cultural tightness-looseness on behavioural innovativeness seems to be completely opposite for the two samples. In this case, it can be asserted that an increase in tightness level for the Turkish sample is likely to negatively influence employees' behavioural tendencies including their willingness to initiate innovative activities and openness to innovation. It should be kept in mind that behavioural innovativeness can be considered as a fundamental factor that underlines innovative outcomes as Wang and Ahmed (2004) p 305 argue. On the other hand, an increase in the cultural tightness level seems to play an encouraging and motivating role on the innovative behaviours of employees for the Italian sample.

\section{Implications}

With the increasing number of multinational companies today cross-cultural studies are gaining greater importance. The success of organizations operating in different cultures depends on their ability to clearly comprehend and internalize the culture in which they engage. It is believed that the cultural dimension of tightness-looseness will provide important hints to managers and key decision makers in acknowledging the cross-cultural differences. Assume a manager in a multinational company, who is supposed to lead a heterogeneous team composed of employees from tight and loose cultures, it is important for him/her to adopt different approaches by considering the cultural characteristics of both groups of employees. While instructions that are so clear and explicit that they do not leave grounds for any doubt are expected to be more motivating for subordinates from tight cultures, instructions that are designed rather freely, open ended and loose in a way that enables employees to take initiatives are more motivating for subordinates coming from loose cultures (Chan et al. 1996) p 11. Similarly, human resources managers in diverse workplaces should pay attention to the cultural characteristics of their labour force when preparing job definitions and designing performance appraisal systems. As individuals of tight societies are more used to showing compliance to predetermined rules and norms, they are expected to be more successful in clearly defined tasks. While adherence to norms is the primary issue in the recruitment processes of tight organizations, in looser organizations whether the candidates' knowledge, skills and capabilities match the requirements of the job plays a crucial role. For instance, the criterion deemed most important is the candidate's quality of being a good organizational citizen and having the capability to show compliance to organizational standards in the recruitment process of Japanese organizations (Morishima 1995).

\section{Limitations and Future Research Directions}

The findings of this study are said to be promising in the sense that they shed new light on the empirical examination of cultural tightness-looseness and its 
relationship with organizational innovativeness in the marble industries of two different countries. Notwithstanding, as every research does, this study inherently has several limitations. The sample of the current study is limited to a single sector and two countries. Thus, researchers should be cautious about generalizing the research findings to other work settings concerning different sectors or industries. It is suggested that further research is needed to test cultural tightness-looseness with several other organizational outcomes in different business environments via confirmatory factor analyses so that its construct validity can be confirmed. It can be seen that cultural tightness-looseness is not the only predictor of organizational innovativeness so that future studies should examine cultural tightness-looseness along with the other dimensions of culture (e.g. individualism-collectivism, power distance, uncertainty avoidance) in order to clearly indicate the concept of tightness-looseness as a distinct dimension of culture in itself.

\section{Conclusion}

The tightness-looseness dimension, as a complementary approach to the values paradigm, is expected to provide important insights for organization scholars and cross-cultural researchers in understanding the complex phenomenon of culture. In this way the research gap left by the value-centric views that are dominating the field can be fulfilled. Furthermore, cultural tightness-looseness dimension should be considered not only at a macro level in societal terms but also as a relevant construct at an organizational level. Within this study the cultural tightness-looseness was put forward as a new dimension in the organizational culture literature and its empirical relationship with organizational innovativeness was sought by adopting a comparative approach to Turkish and Italian marble enterprises. As a result, several exploratory findings were revealed regarding the reliability and validity of the tightness-looseness construct in the workplace and its linkage with organizational innovativeness has been empirically supported.

Acknowledgments We would like to express our gratitude to Prof.Dr. Michele J. Gelfand for all the kind support in adapting tightness-looseness original scale to organizational level.

\section{References}

Aegean Exporters' Associations Sectoral Report (2011) Ed: Prof. Dr. Turgay Onaran İzmir Aiken LS, West SG (1991) Multiple regression: testing and interpreting interactions. Sage, USA Aycan Z (2001) Human resource management in Turkey. Current issues and future challanges. Int J Manpower 22(3):252-260

Aycan Z, Kanungo RN (2000) Toplumsal Kültürün Kurumsal Kültür ve İnsan Kaynakları Uygulamaları Üzerine Etkileri. Türkiye'de Yönetim, Liderlik ve İnsan Kaynakları Uygulamaları. (pp 25-53). Ankara: Türk Psikologlar Derneği Yayınları

Chan DK, Gelfand MJ, Triandis HC, Tzeng O (1996) Tightness-looseness revisited: some preliminary analyses in Japan and the United States. Int J Psychol 31(1):1-12

Ellonen R, Blomqvist K, Puumalainen K (2008) The role of trust in organizational innovativeness. Eur J Innov Manag 11(2):160-181 
Fiş AM, Wasti AS (2010) Yeni Bir Örgüt Kültürü Boyutu: S1k1lık-Esneklik. 18. Ulusal Yönetim ve Organizasyon Kongresi Bildiriler Kitabı (ss 611-618), Düzenleyen Çukurova Üniversitesi 20-22 May1s

Gelfand MJ, Nishii LH, Raver JL (2006) On the nature and importance of cultural tightness and looseness. J Appl Psychol 91:1225-1244

Gelfand MJ, Raver JL, Nishii L, Leslie LM, Lun J, Lim BC et al (2010) The difference between "tight" and "loose" societies revisited: ecological, socio-political, and societal correlates of tightnesslooseness in modern nations. Working paper

Gelfand MJ, Raver JL, Nishii L, Leslie LM, Lun J, Lim BC et al (2011) Differences between tight and loose cultures: a 33-nation study. Science 332(6033):1100-1104

Morishima M (1995) The Japanese human resource management system: a learning bureaucracy. In: Moore ve LF, Jennings PD (ed) Human resource management on the Pacific Rim: institutions, practices, and attitudes. de Gruyter, New York (pp 119-150)

Nunnally JC (1978) Psychometric theory (2nd ed) McGraw-Hill, New York

Pelto PJ (1968) The difference between 'tight' and 'loose' societies. Transaction 5:37-40

Semerciöz F, Hassan M, Aldemir Z (2011) An empirical study on the role of interpersonal and institutional trust in organizational innovativeness. Int Bus Res 4(2):125-136

Toh SM, Leonardelli GJ (2012) Cultural constraints on the emergence of women as leaders. J World Bus 47:604-611

Wang CL, Ahmed PK (2004) The development and validation of the organisational innovativeness construct using confimatory factor analysis. Eur J Innov Manag 7(4):303-313

Wasti A, Fiş AM (2010) Örgüt Kültüründe Sıkılık-Esneklik Boyutu ve Kurumsal Girişimciliğe Etkisi. Yönetim Araştırmaları Dergisi 10:11-32 